\title{
PESQUISA COM EDUCADORES AMBIENTAIS
}

\author{
RESEARCH WITH ENVIRONMENTAL EDUCATORS
}

INVESTIGACIÓN CON EDUCADORES AMBIENTALES

\author{
Inês de Oliveira Noronha \\ Doutora em Educação e Diretora Técnica da Socioambiental Projetos Ltda., Belo Horizonte/MG \\ E-mail: socioambientalprojetos@uol.com.br \\ Arthur Ribas de Souza Sales \\ Engenheiro Ambiental. Consultor da Socioambiental Projetos Ltda - BH/MG \\ E-mail: arthurrssales@gmail.com \\ Clara Toledo Corrêa Oliveira Fonseca \\ Técnica em meio ambiente, CEFET - BH/MG \\ E-mail: claratfonseca@gmail.com
}

\begin{abstract}
RESUMO
Esta é uma pesquisa do tipo Survey, segundo Babbie (1999), desenvolvida no mês de novembro de 2018, pela equipe da Socioambiental Projetos Ltda, cuja coleta de dados se deu através do uso de questionários on line, formulário Google Forms. O objetivo do estudo foi traçar um panorama da aplicação da Educação Ambiental (EA), no âmbito do licenciamento ambiental em Minas Gerais, após a publicação da Deliberação Normativa do Conselho de Política Ambiental de Minas Gerais - COPAM n² 214, de 26 de abril de 2017, a partir da percepção dos Educadores Ambientais do Estado de Minas. O trabalho apresenta perguntas-chave que permitem analisar criticamente a situação da EA, além de permitir um aprofundamento das questões referentes à sua melhoria, sobretudo em relação ao Diagnóstico Socioambiental Participativo.
\end{abstract}

Palavras-chave: Percepção dos Educadores Ambientais; Educação Ambiental; Diagnóstico Socioambiental Participativo; Deliberação Normativa COPAM nº 214/2017.

\begin{abstract}
This is a Survey research, according to Babbie (1999), developed in November 2018, by the team of Socioambiental Projetos Ltda., whose data collection was done through the use of online questionnaires, by Google Forms. The objective of the study was to draw an overview of the application of Environmental Education(EE) in the scope of environmental licensing in Minas Gerais, after the publication of the Normative Deliberation of the Environmental Policy Council of Minas Gerais - COPAM No. 214, of April 26th, 2017, from the perception of the Environmental Educators of the State of Minas Gerais. The paper presents key questions that allow to analyze critically the situation of the Environmental Education, besides allowing a deepening of the questions related to its improvement, especially in relation to the Participative Socio-Environmental Diagnosis.
\end{abstract}


Keywords: Environmental Educators' Perception; Environmental Education; Participative Socio-Environmental Diagnosis; Normative Deliberation COPAM No. 214/2017.

\section{RESUMEN}

Esta es una investigación de tipo Survey, según Babbie (1999), desarrollada en el mes de noviembre de 2018, por el equipo de Socioambiental Proyectos Ltda, cuya recolección de datos se dio por medio del uso de cuestionarios online, formulario Google Forms. El objetivo del estudio fue trazar un panorama de la aplicación de la Educación Ambiental (EA), en el marco del licenciamiento ambiental en Minas Gerais, tras la publicación de la Deliberación Normativa del Consejo de Política Ambiental de Minas Gerais - COPAM n²14, de 26 de abril de 2017, a partir de la percepción de los Educadores Ambientales del Estado de Minas Gerais. El trabajo presenta preguntas clave que permiten analizar críticamente la situación de la EA, además de permitir una profundización de las cuestiones relativas a su mejoramiento, sobre todo con relación al Diagnóstico Socioambiental Participativo.

Palabras-clave: Percepción de los Educadores Ambientales; Educación Ambiental; Diagnóstico Socioambiental Participativo; Deliberación Normativa COPAM n² 214/2017.

\section{INTRODUÇÃO}

Considera-se que a educação ambiental é um direito de todo cidadão e é dever das empresas cumpri-la. De acordo com o Art. 225 da Constituição Federal de 1988, “todos têm direito ao meio ambiente ecologicamente equilibrado, bem de uso comum do povo e essencial à sadia qualidade de vida, impondo-se ao Poder Público e à coletividade o dever de defendê-lo e preservá-lo para as presentes e futuras gerações." (CF, 1988).

Considera-se também que a educação ambiental para uma sustentabilidade equitativa é um processo permanente, baseado no respeito a todas as formas de vida. Tal educação afirma valores e ações que contribuem para a transformação humana e social e para a preservação ecológica. Ela estimula a formação de sociedades socialmente justas e ecologicamente equilibradas, que conservam entre si uma relação de interdependência e diversidade. Isto requer responsabilidade individual e coletiva em nível local, nacional e planetário (ONU, 1992 - Adaptado).

Segundo a Conferência Intergovernamental de Tbilisi (1977), a Educação Ambiental:

é um processo de reconhecimento de valores e clarificações de conceitos, objetivando o desenvolvimento das habilidades e modificando as atitudes em relação ao meio, para entender e apreciar as inter-relações entre os seres humanos, suas culturas e seus meios biofísicos. A educação ambiental também está relacionada com a prática das tomadas de decisões e a ética que 
conduzem para a melhora da qualidade de vida.

De acordo com a Política Nacional de Educação Ambiental, estabelecida pela Lei $\mathrm{n}^{\circ}$ 9.795/1999, em seu Art. $1^{\text {: }}$ :

Entende-se por educação ambiental os processos por meio dos quais o indivíduo e a coletividade constroem valores sociais, conhecimentos, habilidades, atitudes e competências voltadas para a conservação do meio ambiente, bem de uso comum do povo, essencial à sadia qualidade de vida e sua sustentabilidade.

Já a Deliberação Normativa ${ }^{\circ}$ 214/2017, estabelece em seu Art. $2^{\circ}$, inciso I, a seguinte definição sobre Educação Ambiental:

é um processo de ensino-aprendizagem permanente e de abordagem sistêmica, o qual reconhece o conjunto das inter-relações entre âmbitos naturais, culturais, históricos, sociais, econômicos e políticos, com intuito de permitir que os grupos sociais envolvidos com o empreendimento adquiram conhecimentos, habilidades e atitudes para o empoderamento e pleno exercício da cidadania.

Os Programas de Educação Ambiental (PEA) deverão ser estruturados a partir de etapas metodológicas bem definidas, que contemplem obrigatoriamente um Diagnóstico Socioambiental Participativo (DSP). Além das informações coletadas no Diagnóstico Socioambiental Participativo, é importante que o PEA seja elaborado a partir dos estudos ambientais realizados, tendo como referência a tipologia do empreendimento, a atividade licenciada, a área de influência do meio socioeconômico, a realidade local, os grupos sociais afetados e os impactos e danos causados. Ou seja, cada vez mais será necessário o conhecimento, o envolvimento e a participação das comunidades locais nos programas de educação ambiental.

\section{Metodologia}

\section{Tipo de Pesquisa}

Visando atender os objetivos deste trabalho, e ao mesmo tempo, obter da-

1 Diagnóstico Socioambiental Participativo: instrumento de articulação e empoderamento que visa mobilizar, compartilhar responsabilidades e motivar os grupos sociais impactados pelo empreendimento, a fim de se construir uma visão coletiva da realidade local, identificar as potencialidades, os problemas locais e as recomendações para sua superação, considerando os impactos socioambientais do empreendimento. Desse processo, resulta uma base de dados que norteará e subsidiará a construção e implementação do PEA. 
dos que facilitassem traçar um panorama da aplicação da EA no âmbito do licenciamento ambiental em Minas Gerais, após a publicação da DN 214/2017, realizou-se uma pesquisa com os Educadores Ambientais Mineiros para conhecer a sua percepção sobre o tema.

O estudo caracterizou-se como transversal único, no qual se selecionou apenas uma amostra da população-alvo, e as informações foram obtidas somente uma vez.

\section{População e Amostra}

O universo ou população de pesquisa foram os Consultores Ambientais. A amostra foi de 31 indivíduos da planilha de consultores mineiros, mostrada na Figura a seguir, dentre outros selecionados pelos pesquisadores, que consideraram todas as regióes do Estado, todas as regionais contempladas pelas Suprams - Superintendência Regional de Meio Ambiente.

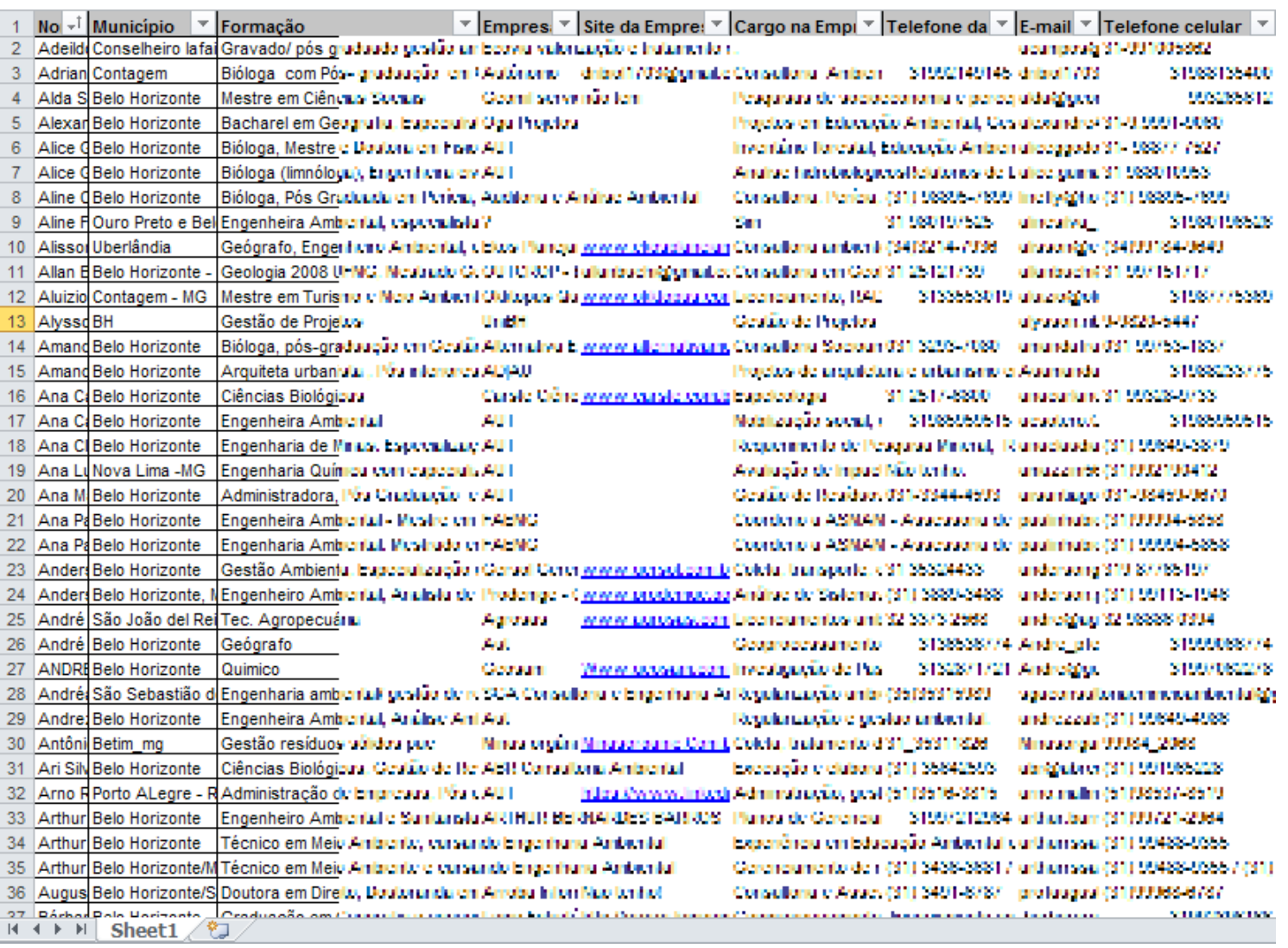

Quadro I - Planilha de Consultores Ambientais de Minas Gerais².

Elaboração: Grupo de Consultores Ambientais, 2016/2019.

2 As informações da imagem estão ilegíveis propositalmente, para preservar os dados pessoais dos educadores ambientais presentes na lista. 
A técnica de amostragem utilizada classificou-se como "não probabilística”, "intencional" e "por conveniência".

\section{Coleta de dados}

Para a coleta de dados foi elaborado um questionário com oito questões semiestruturadas, que foram enviadas através do formulário Google Forms, via e-mail, com confirmação de recebimento e solicitação de retorno.

Apontam-se algumas vantagens atribuídas ao Google Forms tais como: a possibilidade de acesso em qualquer local ou horário; a economia de espaço no disco rígido; o fato de ser gratuito; a facilidade de uso, pois não requer conhecimentos de programação; e uma interface amigável. (DATASCOPE, 2018 - Adaptado)

\section{Análise e tratamento dos dados}

O tratamento dos dados foi realizado por meio de uma análise descritiva. Para tanto, foi utilizado o aplicativo Microsoft Office Excel 2003, para a tabulação e cálculo de frequência dos dados. Além disso, para análise dos dados propriamente dita, foi utilizado o mesmo aplicativo com o suporte de ferramentas estatísticas para apresentação e avaliação dos resultados.

\section{Resultados}




\section{1 - Qual é a sua experiência, em anos, em Educação Ambiental?}



Menos de um ano

Entre 1 e 2 anos

Entre 2 e 3 anos

Entre 3 e 5 anos

Entre 5 e 7 anos

Entre 7 e 10 anos

Entre 10 e 15 anos

Entre 15 e 20

Mais de 20 anos

Figura 1 - Gráfico das respostas coletadas na Questão 01 do formulário «Pesquisa com Educadores Ambientais». Fonte: Autoria própria, 2019.

O objetivo desta pergunta foi verificar a experiência dos profissionais no que se refere ao tempo em anos de atuação em educação ambiental, haja vista que Minas Gerais ainda se apresenta como um Estado carente na área de EA. O gráfico mostra que $25,8 \%$ das pessoas que responderam o questionário têm entre 1 e 2 anos de experiência, enquanto outros 25,8\% têm entre 10 e 15 anos. Já 12,9\% dos respondentes contam com uma experiência de 5 a 7 anos e os outros 12,9\% de 7 a 10 anos. Isto leva a crer que a Deliberação Normativa (DN) parece despertar o interesse das pessoas em relação à educação ambiental. 


\section{2 - De quantos DSPs você participou desde a publicação da DN COPAM 214/2017 até os dias atuais?}

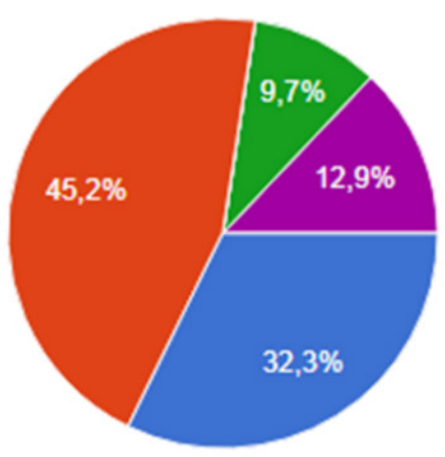

Figura 2 - Gráfico das respostas coletadas na Questão 02 do formulário «Pesquisa com Educadores Ambientais «. Fonte: Autoria própria, 2019.

O objetivo desta pergunta foi quantificar a representatividade de participação dos profissionais nos Diagnósticos Socioambientais Participativos (DSPs), dada a importância da DN 214/2017, a extensão do Estado de Minas Gerais e o número de empresas de significativo impacto que necessitam se regularizar perante o órgão ambiental em relação aos DSPs. O gráfico mostra que 45,2\% dos respondentes assistiram de 1 a 3 DSPs, enquanto que outros 32,3\% não participaram em nenhum. Já 12,9\% dos respondentes estiveram presentes em mais de 10 DSPs, e 9,7\% participaram em 7 a 10 DSPs. Pode-se aferir que ainda há uma parcela representativa de profissionais que não está participando dos estudos da DN 214/2017. Ao mesmo tempo em que a lei despertou o interesse de profissionais novos na área, deixou uma parcela fora do mercado e/ou desatualizada. 


\section{2-A - Se você marcou a opção "Mais de 10", de quantos DSPS exatamente você participou?}

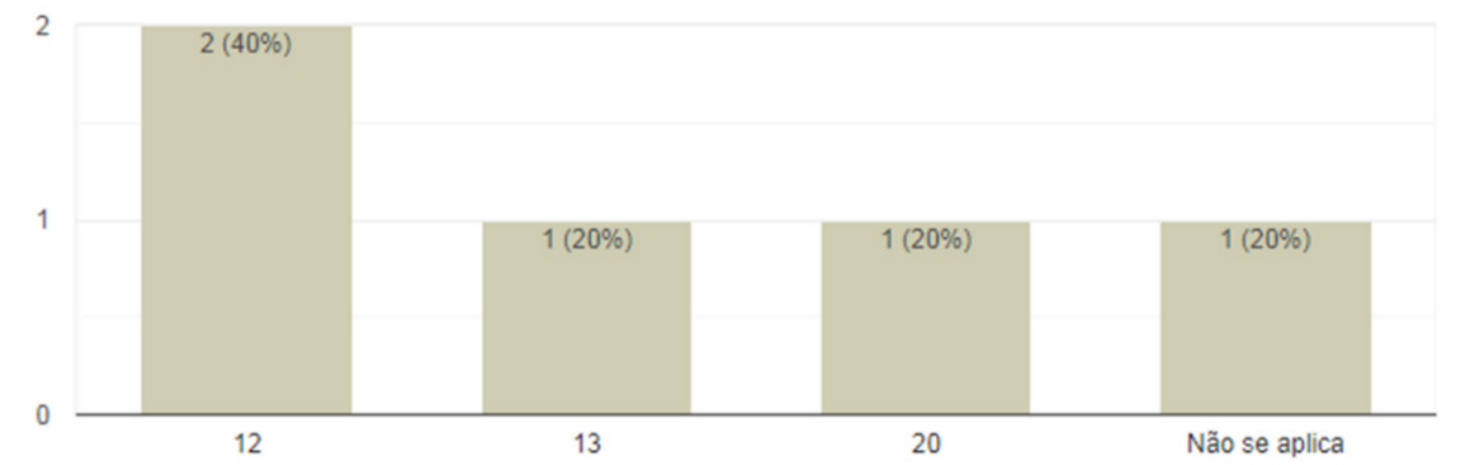

Figura 3 - Gráfico das respostas coletadas na Questão 02 letra A) do formulário "Pesquisa com Educadores Ambientais".

Fonte: Autoria própria, 2019.

O objetivo desta pergunta foi dar sequência à questão anterior, reforçando-a. $O$ gráfico mostra que 2 respondentes afirmaram ter participado de 12 DSPs, o que representa $40 \%$ do total de respondentes, enquanto que um deles afirmou ter participado de 13 DSPs, outro afirmou ter participado de 20 DSPs e outro escreveu "Não se aplica”; cada um destes três últimos representa $20 \%$ do total de respondentes a esta questão.

\section{2-B - Se você marcou a opção "Nenhum", gostaria de ter participado de algum DSP?}

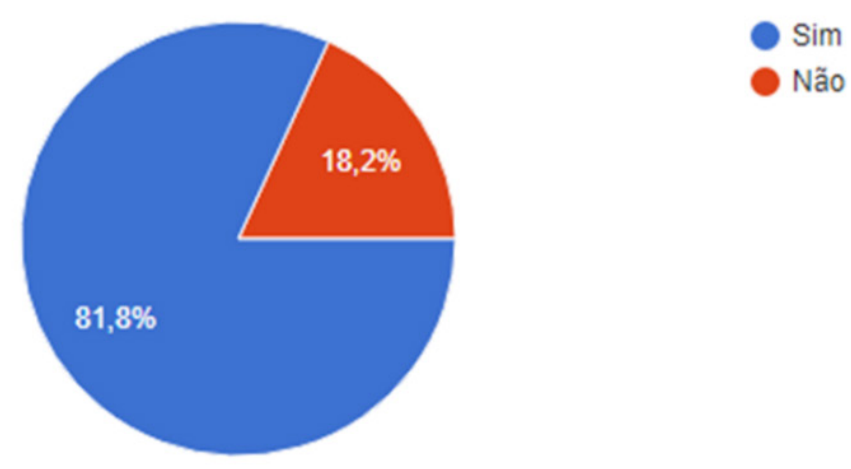

Figura 4 - Gráfico das respostas coletadas na Questão 02 letra B) do formulário "Pesquisa com Educadores Ambientais".

Fonte: Autoria própria, 2019. 
Nesta questão, o objetivo era averiguar o interesse dos profissionais em participar de DSPs, entre aqueles que afirmaram não ter participado de nenhum. A maior parte dos respondentes, que representam $81,8 \%$ do total, afirmaram que têm interesse, enquanto o restante, representando $18,2 \%$ do total, afirmou não estar interessado.

Com relação aos que afirmaram não ter interesse, tal afirmação leva a crer que estes profissionais talvez não se sintam “capacitados” para participar de DSPs.

\section{2-C - Com relação aos DSPs dos quais você participou, você tem conhecimento se houve devolutiva com o público interno e/ou com as comunidades?}


Figura 5 - Gráfico das respostas coletadas na Questão 02 letra C) do formulário "Pesquisa com Educadores Ambientais".

Fonte: Autoria própria, 2019.

Esta questão teve o intuito de avaliar se as devolutivas, ou seja, os feedbacks às comunidades e aos trabalhadores quanto aos resultados do DSP e às ações de Educação Ambiental propostas, estão sendo realizadas. A maior parte dos respondentes, que representam uma parcela de $51,7 \%$ do total, afirmaram não ter conhecimento se houve ou não devolutiva dos DSPs dos quais participaram, enquanto que $41,4 \%$ afirmaram que houve devolutiva e a menor parcela, de 6,9\%, afirmou que não houve nenhuma devolutiva relacionada aos DSPs dos quais participou. 
O grande desconhecimento dos profissionais sobre a realização ou não das devolutivas relacionadas aos DSPs dos quais participaram pode ocorrer devido ao fato de muitas vezes os profissionais ou as consultorias serem contratadas apenas para a realização do DSP, e não na fase da devolutiva.

\section{2-D - Com relação a estas devolutivas, você participou de alguma?}

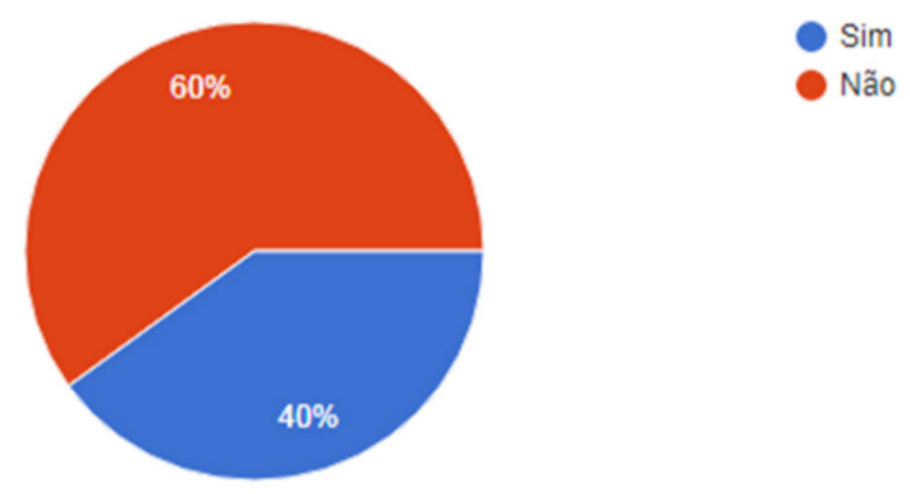

Figura 6 - Gráfico das respostas coletadas na Questão 02 letra D) do formulário "Pesquisa com Educadores Ambientais".

Fonte: Autoria própria, 2019.

Esta questão deu sequência à anterior, perguntando aos 41,4\% que afirmaram que houve devolutiva se eles tiveram participação nelas. A maior parte dos respondentes, $60 \%$ do total, afirmou não ter participado das devolutivas dos seus DSPs, enquanto o restante, 40\%, afirmou ter participado.

Este resultado pode ser justificado da mesma forma que na questão anterior, pelo fato de que muitas vezes os profissionais e consultorias não são contratados para realizar as devolutivas dos DSPs dos quais participam. 
3 - Em 2017 o estudo realizado com os consultores ambientais mineiros apontou os itens e os percentuais que mostram o gráfico abaixo. A partir da sua observação do gráfico, qual é a sua opinião a respeito do panorama 2017 -2018? Houve mudanças?



Figura 7 - Enunciado referente à Questão 03 do formulário "Pesquisa com Educadores Ambientais". Fonte: Autoria própria, 2019. 
3 - Em 2017 o estudo realizado com os consultores ambientais mineiros apontou os itens e os percentuais que mostram o gráfico abaixo. A partir da sua observação do gráfico, qual é a sua opinião a respeito do panorama 2017 -2018? Houve mudanças?



a) Sim

b) Não

c) Não sei responder

d) Prefiro não opinar

e) A Educação Ambiental em Minas Gerais mudou em alguns aspectos do gráfico, mas não em todos.

Figura 8 - Gráfico das respostas coletadas na Questão 03 do formulário "Pesquisa com Educadores Ambientais".

Fonte: Autoria própria, 2019.

Nesta questão, os respondentes analisaram o gráfico de barras mostrado inicialmente, que sintetiza os resultados de outra pesquisa realizada no ano de 2017, para então responder ao questionamento principal, que pretendia avaliar se houve ou não mudanças nos principais entraves dos Programas de Educação Ambiental em Minas Gerais, de acordo com a percepção de cada um.

A maior parte dos respondentes, 45,2\% do total, afirmou que a Educação Ambiental em Minas Gerais mudou em alguns aspectos do gráfico, porém não em todos; enquanto uma parcela de 25,8\% afirmou não saber responder à pergunta. Outros 19,4\% afirmaram que não houve mudanças, enquanto que uma parcela mínima afirmou que houve mudanças e o restante preferiu não opinar.

Este resultado mostra que os Educadores Ambientais mineiros ainda encontram entraves e dificuldades na elaboração e aplicação dos Programas de Educação Ambiental em Minas Gerais, mesmo após mais de um ano da publicação da DN COPAM 214/2017. 


\section{3-B - Se você selecionou as opções a) ou e) na questão anterior, quais itens citados no gráfico acima avançaram em sua percepção?}
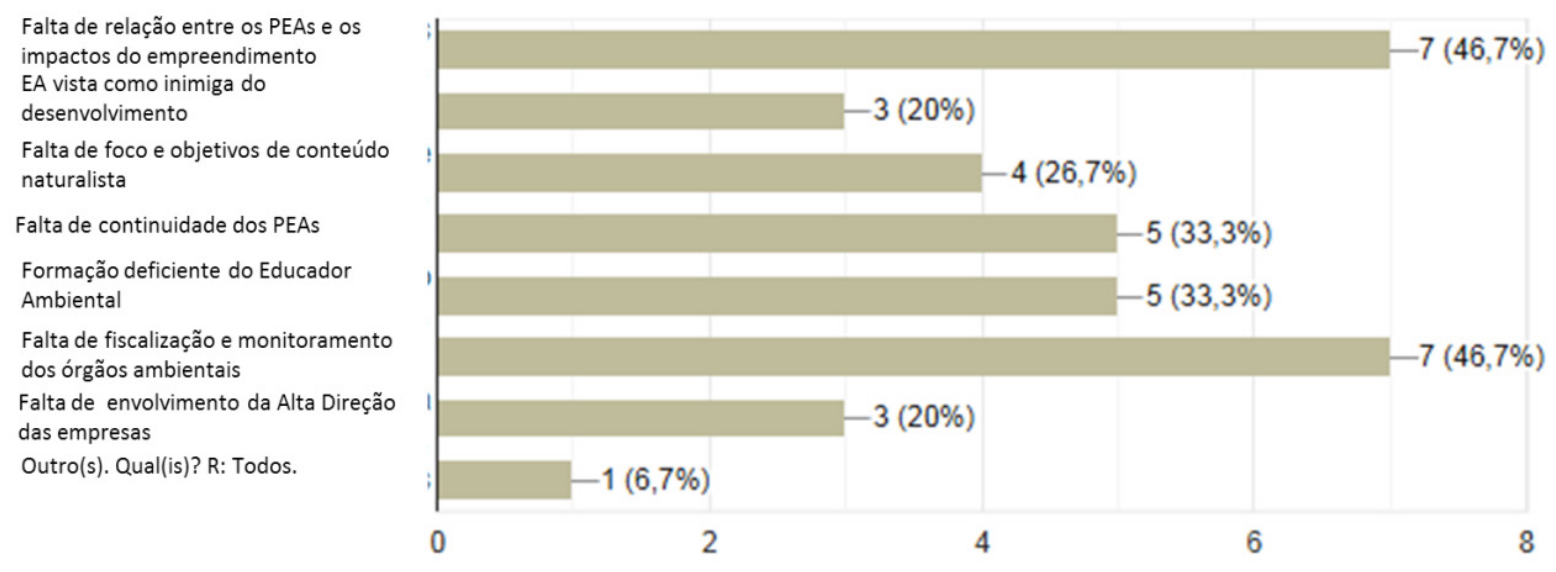

Figura 9 - Gráfico das respostas coletadas na Questão 03 letra B) do formulário "Pesquisa com Educadores Ambientais".

Fonte: Autoria própria, 2019.

Esta questão dá continuidade à anterior, perguntando aos respondentes que afirmaram que houve mudanças no panorama 2017-2018 da Educação Ambiental e também aos que informaram que a Educação Ambiental mudou em alguns aspectos, mas não em todos, sobre quais itens do gráfico de barras apresentaram alguma melhora no último ano.

Nesta questão os respondentes poderiam selecionar mais de uma opção, portanto as opções mais selecionadas foram a melhora na relação entre os PEAs e os impactos do empreendimento e a melhora na fiscalização e monitoramento dos órgãos ambientais. Em seguida, as opções mais selecionadas foram a melhora na continuidade dos PEAs e na formação do Educador Ambiental, seguidas pela melhora no foco e objetivos de conteúdo naturalista, a melhora no conceito de que a EA é vista como inimiga do desenvolvimento, e a melhora no envolvimento da Alta Direção das empresas. Apenas um respondente selecionou a opção "Outro(s)", citando todas as alternativas como exemplo. 


\section{3-C - Em sua opinião a que se deve esse avanço?}

- "O setor produtivo e a alta direção das empresas tem percebido de forma mais clara a importância da Educação Ambiental."

- "Acredito que a DN 214."

- "Maior cobrança dos órgãos ambientais."

- "DN 214."

- "Aos novos termos propostos."

- "Ao próprio escopo do DSP, no entanto, ainda existe resistência por parte dos empreendedores que em alguns casos acho que por receio, não querem fazer um instrumento que envolva toda a comunidade e sim por partes."

- "Consciência humana."

- "A DN."

Figura 10 - Gráfico das respostas coletadas na Questão 03 letra C) do formulário "Pesquisa com Educadores Ambientais".

Fonte: Autoria própria, 2019.

Esta questão se dirigia especificamente àqueles que responderam à pergunta anterior. Os respondentes tiveram a liberdade de discorrer sobre os fatores que, de acordo com sua percepção, justificam o avanço dos aspectos destacados anteriormente.

Nota-se que as opiniões são diversificadas, mas percebe-se que três opiniões citam a própria existência da DN COPAM 214/2017 como a justificativa para os avanços. Destacam-se também a duas opiniões, de dois respondentes diferentes, que divergem entre si. A primeira afirma que "o setor produtivo e a alta direção das empresas têm percebido de forma mais clara a importância da Educação Ambiental”, enquanto que a segunda afirma que, mesmo com as melhorias, "[...] ainda existe resistência por parte dos empreendedores $[\ldots] "$.

Isto mostra que os Educadores Ambientais têm vivido diferentes experiências durante seus trabalhos com Educação Ambiental, da mesma forma que empreendedores têm recebido as propostas e ações de maneiras diferentes. 
3-D - Se você selecionou a opção NÃO na questão 3, em sua percepção, a que se deve essa "estagnação"? (Caso não deseje responder, deixe a questão em branco)

- "Essa estagnação deve-se ao distanciamento ou a inexistência das relações entre comunidade/empreendimento."

- "Falta de integração das ações de educação ambiental."

- "Falta de interesse tanto da empresa, quanto da população."

- "Continua a falta de envolvimento da alta direção."

- "Coerência nas políticas com a prática."

Figura 11 - Lista de respostas coletadas na Questão 03 letra D) do formulário "Pesquisa com Educadores Ambientais".

Fonte: Autoria própria, 2019.

Esta questão foi dirigida especificamente aos respondentes que afirmaram que a Educação Ambiental não apresentou nenhuma melhoria desde a publicação da DN COPAM 214/2017 até o momento da realização da pesquisa. Nela, os respondentes poderiam informar a que fato(s) se deve a estagnação nos aspectos da Educação Ambiental relatados na questão 3.

Nota-se que as opiniões foram bastante diversificadas, e uma colocação a ser destacada é a que afirma a "continua a falta de envolvimento da alta direção", que se enfrenta ao que outro respondente afirmou na questão anterior, com relação aos avanços da Educação Ambiental: “o setor produtivo e a alta direção das empresas têm percebido de forma mais clara a importância da Educação Ambiental”.

Isto reforça ainda mais aquilo que foi possível perceber na questão anterior, que os Educadores Ambientais têm vivenciado diferentes experiências e se deparado com diferentes cenários durante sua atuação, o que torna a Educação Ambiental um campo de atuação bastante dinâmico. 


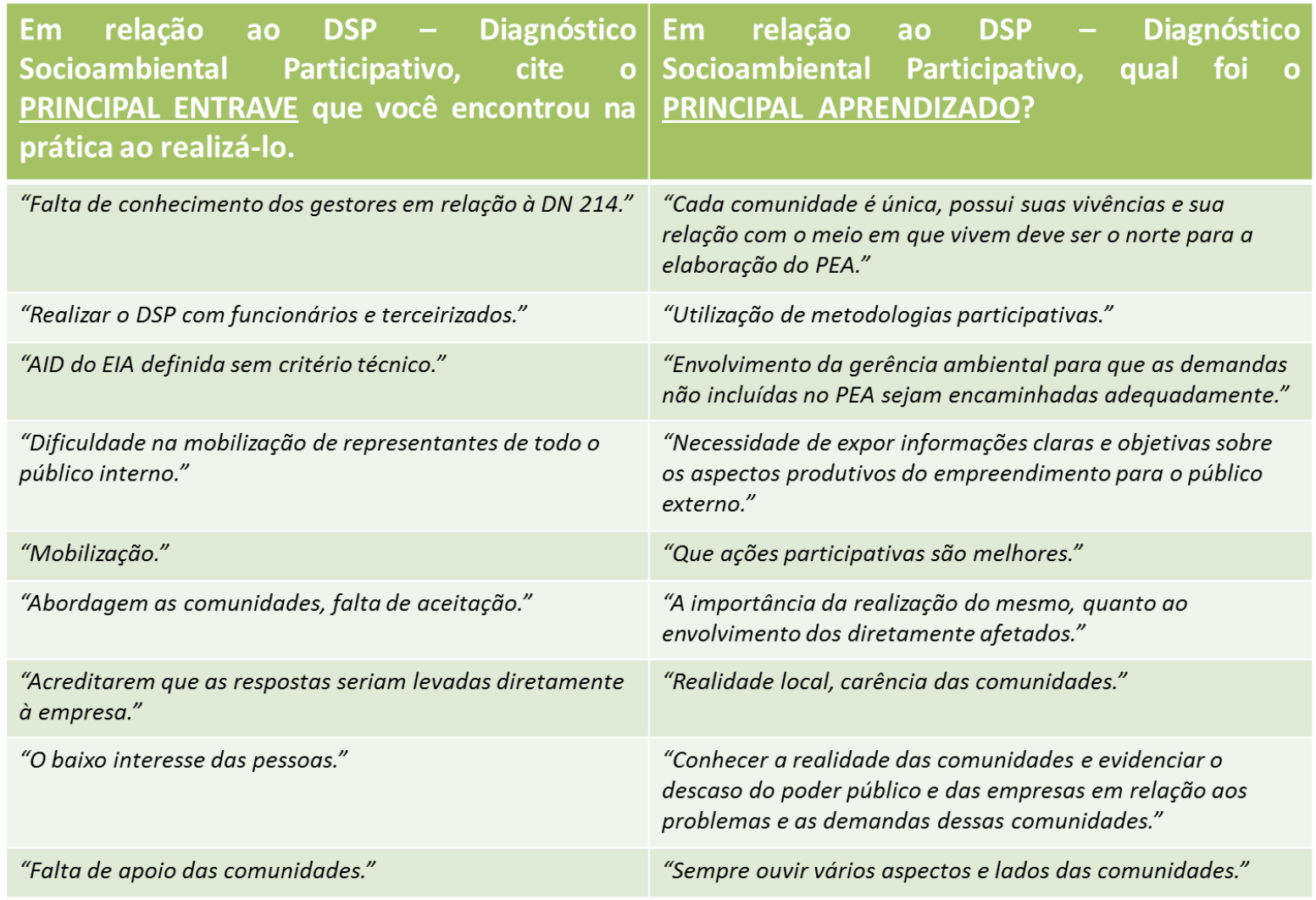

Quadro II - Tabela de respostas referentes às Questões 04 e 05 do formulário "Pesquisa com Educadores Ambientais".

Fonte: Autoria própria, 2019.

\begin{tabular}{|c|c|}
\hline $\begin{array}{l}\text { Em relação ao DSP }- \text { Diagnóstico } \\
\text { Socioambiental Participativo, cite o PRINCIPAL } \\
\text { ENTRAVE que você encontrou na prática ao } \\
\text { realizá-lo. }\end{array}$ & $\begin{array}{l}\text { Em relação ao DSP - } \\
\text { Socioambiental Participativo, qual foi } 0 \\
\text { PRINCIPALAPRENDIZADO. }\end{array}$ \\
\hline
\end{tabular}

"Periodicidade proposta pela empresa."

"O empreendedor não queria utilizar um instrumento participativo."

"A comunidade ainda vê como troca de favores, empregos, ajuda financeira em festas, etc."

"Disponibilidade dos moradores."

"As empresas aceitarem o Diagnóstico."

"Dificuldade do público externo em entender o propósito do DSP."

"Não encontrei entrave algum. Todos os municípios foram abertos para aplicação dos mesmos."

"Interesse e conhecimento da sociedade."
"Se adequar às demandas do empreendimento."

"A proximidade da comunidade com o empreendimento pode auxiliar e muito nas motivações de impacto causados por este e também melhorar o relacionamento da empresa com a comunidade."

"Aprimoramento em metodologias de aplicação."

"Os anseios reais da comunidade local."

"Mobilização das comunidades."

"Aprender como se posicionar perante a comunidade e como lidar em determinadas situações."

"Participação maior dos empreendimentos."

"A motivação social, quando envolvidos e estimulados."

Quadro III - Tabela de respostas referentes às Questões 04 e 05 do formulário "Pesquisa com Educadores Ambientais".

Fonte: Autoria própria, 2019. 
Os quadros acima mostram os resultados de duas questões diferentes, que indagavam sobre os principais entraves e os principais aprendizados dos profissionais durante a realização de DSPs.

Os resultados foram dispostos desta forma para alinhar, lado a lado, as diferentes colocações dos mesmos respondentes, para cada questão. Ou seja, cada linha do quadro representa as respostas de um mesmo profissional para cada pergunta, respectivamente.

Desta forma, é possível notar os entraves e os aprendizados de cada profissional durante a prática dos DSPs. Entre os entraves, nota-se que o mais recorrente foi a dificuldade na mobilização das comunidades para o DSP. Já entre os aprendizados, não houve uma colocação recorrente, pois os aprendizados foram diversos e refletem o quanto cada profissional absorveu durante as suas experiências.

\section{6 - Qual(is) metodologia(s) você mais utilizou com o público interno no DSP?}

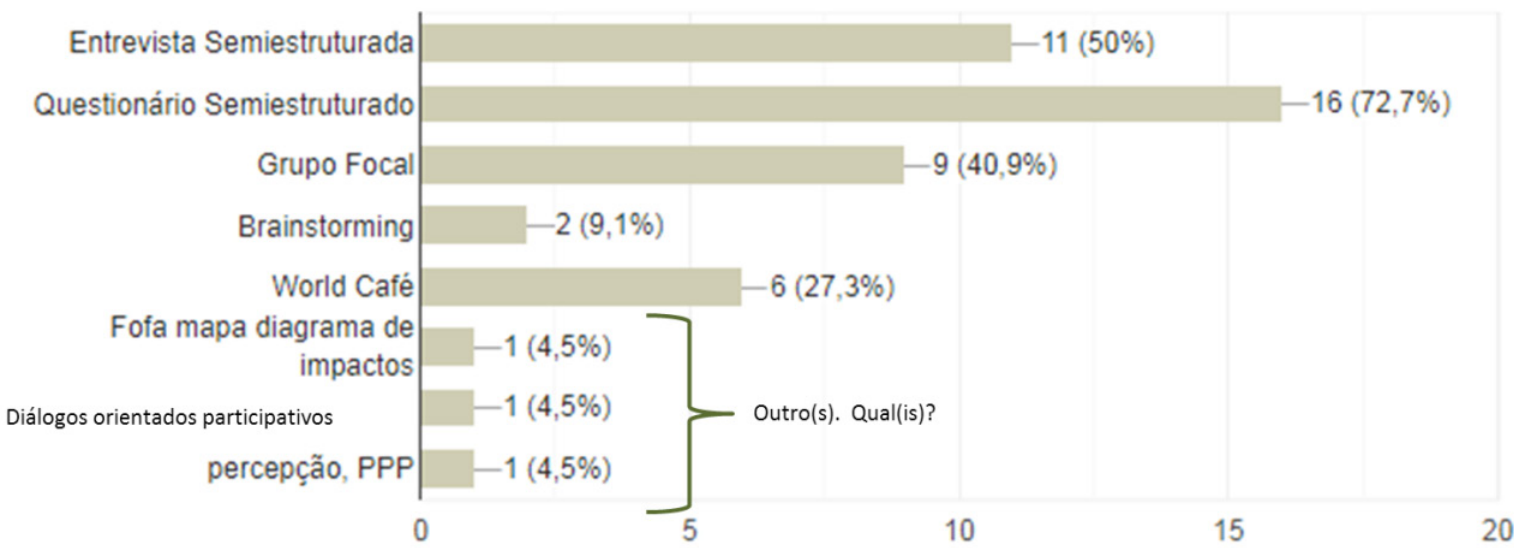

Figura 12 - Gráfico das respostas coletadas na Questão 06 do formulário “Pesquisa com Educadores Ambientais".

Fonte: Autoria própria, 2019.

Nesta questão, os respondentes deveriam informar qual ou quais metodologias eles mais utilizaram com o público interno em seus DSPs. As cinco primeiras foram dadas como opções que eles poderiam selecionar, e ainda havia uma opção "Outros” na qual eles 
tiveram liberdade para indicar as metodologias que utilizaram, caso não as encontrassem nas opções sugeridas.

A opção mais selecionada foi o questionário semiestruturado, por 72,7\% do total de respondentes, seguida pela entrevista semiestruturada, selecionada por $50 \%$ do total, enquanto que a terceira opção foi o Grupo Focal, representada por 40,9\% do total. As duas alternativas menos representadas foram o World Café (27,3\%) e o brainstorming (9,1\%).

Entre os que selecionaram a opção "Outros", as metodologias informadas foram a matriz FOFA (Forças, Oportunidades, Fraquezas e Ameaças), mapas e diagrama de impactos, informadas pelo mesmo respondente; os diálogos orientados participativos, informados por outro; e a percepção e a PPP, informadas por um terceiro.

\section{7 - Qual(is) metodologia(s) você mais utilizou com o público externo no DSP?}

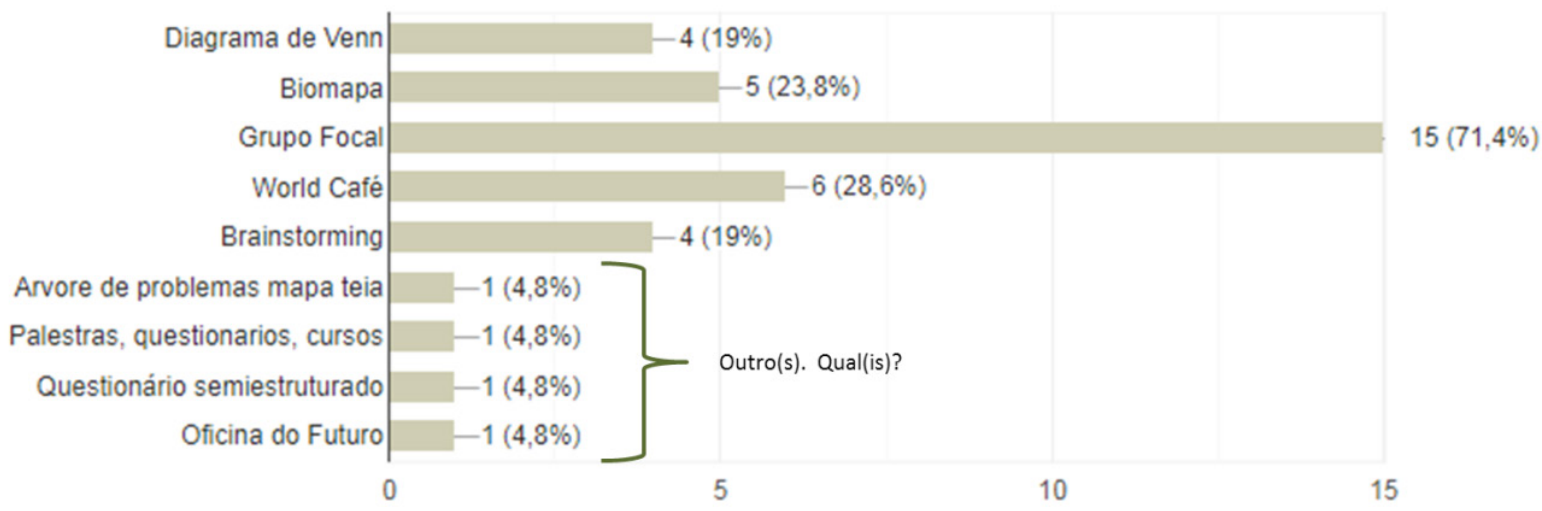

Figura 13 - Gráfico das respostas coletadas na Questão 07 do formulário "Pesquisa com Educadores Ambientais".

Fonte: Autoria própria, 2019.

Nesta questão, os respondentes deveriam informar quais foram as metodologias que mais utilizaram com o público externo em seus DSPs; tinham cinco opções sugeridas que poderiam selecionar e ainda a opção "Outros", na qual poderiam escrever as metodologias que utilizaram e que não se enquadravam nas sugestões.

A metodologia mais utilizada pela maioria dos respondentes, $71,4 \%$ do total, foi o 
Grupo Focal, seguida pelo World Café (28,6\%), pelo biomapa (23,8\%) e pelo Diagrama de Venn e Brainstorming, empatados com $19 \%$.

Quanto aos que selecionaram a opção “Outros”, as metodologias informadas foram a Árvore de Problemas, mapas e teias; palestras, questionários e cursos; questionário semiestruturado; e Oficina do Futuro, cada uma destas informada por uma pessoa diferente.

\section{8 - Quais foram as principais demandas das comunidades em relação aos PEAs?}

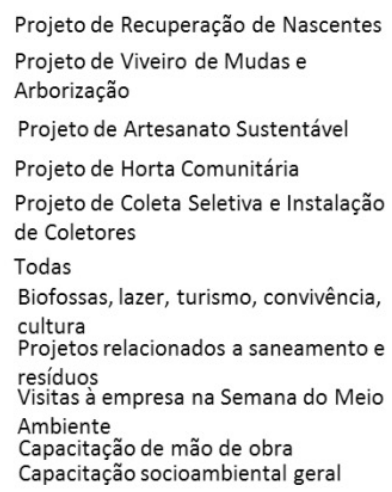

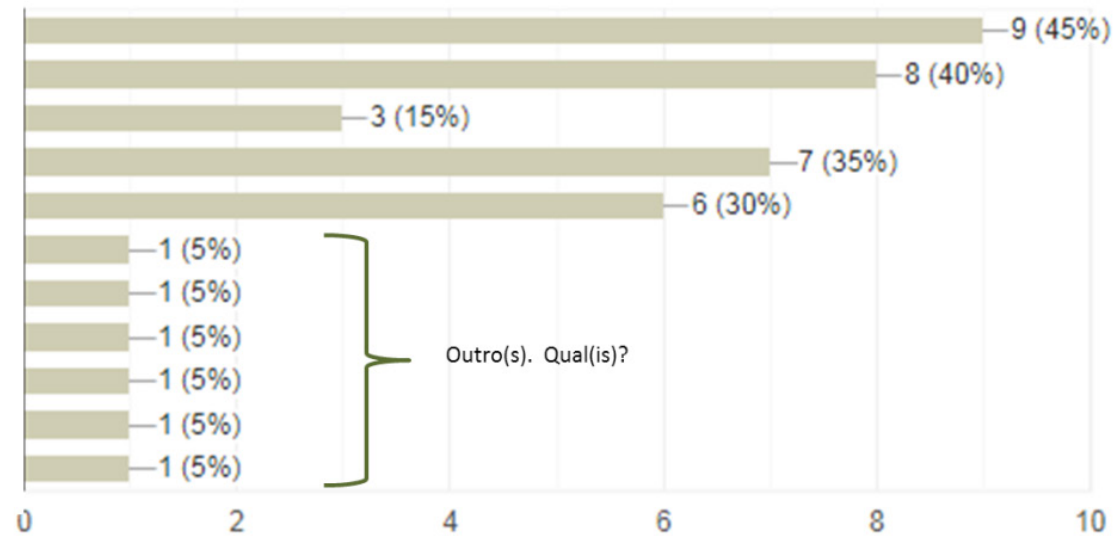

Figura 14 - Gráfico das respostas coletadas na Questão 08 do formulário "Pesquisa com Educadores Ambientais".

Fonte: Formulário "Pesquisa com Educadores Ambientais", 2019.

Nesta última questão, os respondentes deveriam informar quais foram as principais demandas relacionadas à Educação Ambiental das comunidades com as quais realizaram seus DSPs; contavam com cinco opções sugeridas que poderiam selecionar, inclusive podiam selecionar mais de uma, e tinham a liberdade de relatar outros itens através da opção “Outro(s)".

O gráfico mostra que as principais demandas relatadas pelos respondentes desta pesquisa foram respectivamente: Projeto de Recuperação de Nascentes, Projeto de Vivei- 
ro de Mudas e Arborização, Projeto de Horta Comunitária, Projeto de Coleta Seletiva e Instalação de Coletores e Projeto de Artesanato Sustentável.

Entre aqueles que selecionaram a opção "Outro(s)", as demandas relatadas foram "Biofossas, lazer, turismo, convivência, cultura", "Projetos relacionados a saneamento e resíduos", "Visitas à empresa na Semana do Meio Ambiente", "Capacitação de mão de obra”, "Capacitação socioambiental geral”.

\section{CONSIDERAÇÕES FINAIS}

De forma geral, a pesquisa demonstrou que a Deliberação Normativa COPAM $n^{\circ}$ 214/2017 dividiu opiniões entre os Educadores Ambientais, no que diz respeito à sua aplicabilidade e às mudanças em relação à forma como a Educação Ambiental era aplicada antes de sua publicação.

Ao mesmo tempo em que trouxe melhorias, novos conceitos e uma nova forma de se utilizar a Educação Ambiental dentro do licenciamento ambiental, os profissionais mesmo os mais experientes- demonstraram ter se deparado com algumas dificuldades e algumas dúvidas em relação com as disposições da Deliberação.

Ainda assim, mesmo com as dificuldades encontradas, é notório que o Diagnóstico Socioambiental Participativo, principal ferramenta trazida pela Deliberação, apresentou uma inovação ao permitir que as partes interessadas, ou seja, os trabalhadores dos empreendimentos licenciados e as comunidades de suas áreas de influência participassem do processo de construção dos projetos de Educação Ambiental que serão dirigidos a eles próprios, tendo como base a sua realidade socioambiental e seu conhecimento sobre o local onde vivem.

Esta pesquisa mostra que ainda há muito que avançar no que diz respeito à Educação Ambiental em Minas Gerais, e que são necessárias muitas discussões e análises da Deliberação Normativa COPAM n² 214/2017 para sua interpretação concisa e sua correta 
aplicação.

\section{REFERÊNCIAS}

BABBIE, E. Métodos de pesquisas de survey. Belo Horizonte: Editora UFMG, 1999, 519 p.

BRASIL. Constituição Federal de 1988. Promulgada em 5 de outubro de 1988. Disponível em: http://www.planalto.gov.br/ccivil_03/Constituicao/Constituicao.htm. Acesso em:

BRASIL. Lei n 9.795, de 27 de abril de 1999. Dispõe sobre a educação ambiental, institui a Política Nacional de Educação Ambiental e dá outras providências. Brasília, Diário Oficial da União, 28 abr. 1999.

CONFERÊNCIA INTERGOVERNAMENTAL SOBRE EDUCAÇÃO AMBIENTAL. Declaração de Tbilisi. Disponível em: http://www.mma.gov.br/port/sdi/ea/deds/pdfs/decltbilisi.pdf. Acesso em: 23 jan. 2019.

MINAS GERAIS. Conselho Estadual de Política Ambiental. Deliberação Normativa COPAM $\mathbf{n}^{\circ}$ 214, de 26 de abril de 2017. Estabelece as diretrizes para a elaboração e a execução dos Programas de Educação Ambiental no âmbito dos processos de licenciamento ambiental no Estado de Minas Gerais. Belo Horizonte, Diário do Executivo de Minas Gerais, 29 abr. 2017.

ORGANIZAÇÃO DAS NAÇÕES UNIDAS. Conferência das Nações Unidas sobre Meio Ambiente e Desenvolvimento. Tratado de Educação Ambiental para Sociedades Sustentáveis e Responsabilidade Global. 1992. Disponível em: http://www.mma.gov.br/ educacao-ambiental/formacao/item/8068-tratado-de-educa\%C3\%A7\%C3\%A30-ambiental-para-sociedades-sustent\%C3\%A1veis-e-responsabilidade-global.html. Acesso em: 25 jan. 2019.

Vantagens e desvantagens do Google Forms. Disponível em: http://www.mydatascope. com/blog/pt/2018/10/03/vantagens-e-desvantagens-do-google-forms/. Acesso em: 23 jan. 2019.

Recebido em: 05/07/2019

Parecer em: 06/11/2019

Aprovado em: 08/11/2019 